\title{
Transmedial Worlds - Rethinking Cyberworld Design
}

\author{
Lisbeth Klastrup \& Susana Tosca \\ Center for Computer Games Research \\ IT University of Copenhagen \\ klastrup@itu.dk \& tosca@itu.dk
}

\begin{abstract}
In this paper we introduce the concept of transmedial worlds, relating it to genre and adaptation theory, and presenting a framework for how to look for transmedial traits in a world. Through some examples, we argue that applying this concept to the analysis of cyberworlds can reveal interesting results, as well as being a useful tool for designers of cyberworlds to plan their content.
\end{abstract}

\section{Introduction}

Certain universes stick with us - Middle Earth, the Star Wars Galaxy, or the Cthulu Mythos - and they have such devoted followers that recreating the universe in another media form is almost a sure success. But what defines a successful universe that can be transported across media - or as we will call it here - a transmedial world? This paper puts forward the idea that in thinking about and designing cyberworlds, we could take some inspiration from transmedial worlds. The paper is part of a bigger ongoing investigation about transmedial worlds.

\section{A definition of transmedial worlds (TMW)}

We propose the following definition of transmedial worlds (in what follows referred to as TMW):

Transmedial worlds are abstract content systems from which a repertoire of fictional stories and characters can be actualized or derived across a variety of media forms. What characterises a transmedial world is that audience and designers share a mental image of the "worldness" (a number of distinguishing features of its universe). The idea of a specific world's worldness mostly originates from the first version of the world presented, but can be elaborated and changed over time. Quite often the world has a cult (fan) following across media as well.

Subjects interacting with the transmedial world in any of its actualizations (for example a book, a film, a game...) can recognize the world by its abstract properties. Thus, for example, subjects are able to judge if a novel that expands the story of one of the supporting characters in a film (like the Star Wars canteen novels) fits into the Star Wars universe or not; or are able to discern that swearing is out of place in the Lord of the Rings world. In our definition, a transmedial world is more than a specific story, although its properties are usually communicated through storytelling. For example, the transmedial world of Tolkien's Middle Earth is more than the particular book trilogy called The Lord of the Rings, and it includes the films, the board games, the computer games, the fan fiction, the landscapes painted by graphic artists, etc. The point is that by encountering one of the world's actualizations (for example an amusement park ride in which participants have to shoot arrows at cardboard orcs), the imaginary construct of the world is evoked in the participant's imagination, and each simple act gains a much wider meaning.

A transmedial world can initiate in any medium; the Lord of the Rings world originated from novels, the Star Wars world from films and the Pokemon world from a Nintendo Gameboy game. It can be orchestrated by a corporation that controls the different media incarnations or appear spontaneously due to fan activity and independent incarnations. In any case, it is impossible to predict that a certain object will originate a transmedial world just by looking at the object itself. Its success depends on the way that the interpretive community (Fish [6]) has received the originating object (novel, film, game etc) and has been interested in expanding its world by either consuming related objects in different media or even creating their own objects within the transmedial world, such as fan fiction or table top roleplaying games, characters and adventures.

Such as in the case of cult literature and film, transmedial worlds are often the object of near worship by their fans (indeed some transmedial worlds originate from cult objects, such as Lovecraft's horror writing), but are not only limited to small numbers of followers, as some of the most recognizable transmedial worlds have millions of fans and originate from big blockbusters (i.e. Star Wars).

The concept of transmedial worlds is very related to that of genre, as it has been described in literature and film theory. Genre is a descriptive and normative concept 
at the same time and depends on general recognition within an interpretive community :

"Genres can be defined as patterns / forms / styles / structures which transcend individual art products, and which supervise both their construction by artist and their reading by audiences” (Ryall quoted in Lacey [13: p.132]

Genres are part of what readers/users know (part of their repertoire, in Iser's terms [8, p.69]; something they need to apply in order to decode texts. A requirement for a genre to exist is that more than one single product shares the basic structure so as to be recognizable by audiences. Genres occur within one media, and often translate to other media (with different conventions according to the nature of each medium), for example there are science fiction books, films and computer games.

A transmedial world works interpretively in the same way as a genre, with the difference that all the products / incarnations share a basic foundational story and there is only one acceptable version of an ethos, topos and mythos (see below). A genre allows for minor variations (think for example of the very different ethos of Alien and Starship Troopers, both science fiction films). If genres are themes, transmedial worlds are themes plus a common background story, which makes them narrower in scope, but also means that its incarnations are more coherent and homogeneous than those of a genre.

Nick Lacey has proposed a list of what is part of any genre, or what do we look at when applying our mental genre schemata to things: setting, character, narrative, iconography, style and stars [13: p.136], which he then uses to describe several different genres (western, film noir, etc.). His list is not unlike our model of transmedial context production, with the difference that ours contains specific categories for cyberworlds, and we are specially interested in interactivity and performance.

The moment that a reader/viewer identifies a genre, all the recognizable conventions apply, and it is the same when receiving (film, book) and when performing (computer game, writing fan fiction, roleplaying). We argue that the same happens in transmedial worlds.

\section{What transmedial worlds are not}

We have been inspired by other author's work in our conceptualization of transmedial worlds.

Henry Jenkins talks about transmedia storytelling [9] referring to general media convergence in the entertainment industry, a phenomenon he is critical about as sequels are, according to him, very often redundant, watered down or full of contradictions [9].

Successful sequels have emerged from creators with a single vision, like George Lucas, or rich environments from authors that conceived of their art as worlds, such as
J.R.R. Tolkien. To Jenkins, the key is not only that each franchise must be self-contained, but also that each medium concentrates in exploiting its strengths: a story could be introduced in a film, expanded through a novel and "its world might be explored and experienced through game play" [9]. We do not think his mention of games as a good medium to support worlds is casual, but that it implicitly points to the fact that the exploration activity that cyberworlds allow for is a very substantial advantage over other media when trying to bring a world to life.

Jenkin's perspective is interesting because it balances both the corporate and the consumption perspectives, and it is based on a few examples of good ways of translating stories (the young Indiana Jones tales, the Star Wars Canteen novels). The difference is that he focuses on the concrete telling of one story through different media, and our transmedial world concept is about the abstract properties that cut across the different manifestations.

On parallel lines to Jenkins, the narratologist MarieLaure Ryan has worked with the concept of transmedial narrative. In a recent conference paper ${ }^{1}$, she stated that she perceives of narrative as a transmedial phenomenon whose identity lies “entirely in the signified”. By this she means that narrative is a certain type of mental image, or cognitive construct which can be isolated from the stimuli that trigger its construction. Therefore narrative is independent of the medium in which it is represented - it is a "script" which is evoked (see also [17]). According to Ryan, all narrative scripts involve a world populated with events and objects, and the change of the state of this world, through actions and happenings, which seen in connection can be seen to form a plot.

Even if there are some similarities between her theory and ours, she foregrounds "narrativity" as the key element in the abstract, mental worlds, she discusses. For us, even if a transmedial world can have narrative, it is not the sole defining characteristic, or will not always be there in a recognizable plottable form. Especially in cyberworlds, dramatic events are something that emerge, not something that exist in the world a priori.

Another related theory is Piotr Sitarski's development of Marsha Kinder's entertainment systems concept in relationship to computer games [18]. An entertainment system is "a network of texts organised around a figure or group of figures from popular culture”, such as for example the Resident Evil series of games and the film of the same name. Entertainment systems replace individual texts in that the narrative is subordinated to the

\footnotetext{
${ }^{1}$ Marie-Laure Ryan: "Transmedial Narratology and Concepts of Narrative", 2nd International Colloquium on "Narratology beyond Literary Criticism, University of Hamburg, 20.-22. November 2003.
} 
characters, and particular events; one of his examples is the Mortal Kombat film plot, which cannot be explained by narrative logic but by the need to adapt to a preexisting videogame. [18].

His approach is interesting because it points to the very close relationship between contemporary products of the same franchise, and explains new narrative anomalies $^{2}$ that force audiences to consume several products of the same franchise in order to experience a complete story. Talking in Iser's terms [8: p.169], we could say that in an entertainment system, some of the gaps cannot be filled in by readers/viewers, because the necessary information lies outside the text, in another text.

However, his concept is different from ours in that it is centered on particular plot developments in specific texts (and also very much in characters). We disagree with the idea that there is no original text in entertainment systems. To us, original texts that spin off worlds, such as Tolkien's books, very often acquire a cult status. Any new interpretation or instantiation is closely followed by fans, who will anathemize deviations with nearly religious zeal.

Finally, Jesper Juul talks about transmedial games in Half-Real. Video games between real rules and fictional rules, where he points to the fact that computer games, just like narrative, do not depend on one particular medium to exist, and can actually be translated across them [10].

Like Jenkins, Juul insists on the idea that different media have different strengths. We have been inspired by his use of the word transmedial, but our approach does not focus on the structural properties of games or narrativity understood as a particular sequence of events. A focus on worlds allows us to go beyond a mediacentered theoretical perspective and concentrate instead on the abstract content system itself and how it is experienced.

\section{Transmediality and adaptation theory}

If we look to other theoretical influences on our theory, there is a natural link between concepts of transmediality and adaptation theory. This field of study has mainly discussed the adaptation of works from book to film, but in principle deals with all media forms; an early piece on adaptation was Lessing's famous Laocoon discussion of “adaptation” between painting and poetry.

\footnotetext{
${ }^{2}$ A good example of a narrative anomaly, in this case the omission of an important plot point, is in the film The Matrix Reloaded (2003), where the story of how Niobe's team manages to cut the electrical power down so that the heroes can succeed in their final mission is never shown, because it is part of the videogame (Enter the Matrix, 2003) action that the player must complete herself.
}

Both transmedial thinking and adaptation theory address the question of how "content" can move between different platforms (verbal, pictorial, auditory etc). However, much adaptation theory in fact defines and points to the essential meaning-making properties of a particular media form. Novels and other narrative texts are seen as media genres which foreground time; film and games as media genres which foreground space etc. (see for instance [1] or [4]).

We are looking at worlds which can be organised and presented in any media form and in which both the rendering of space and the sense of history (time passing) are important. We do not want to claim that some media forms are better at presenting worlds than other, though we believe that each media form has particular advantages. In general, when analysing transmedial worlds, it makes no sense to examine issues of literal adaptation, but adaptation theory might nevertheless help us to understand processes of meaning-making, of "recoding" of the world and the importance of fidelity to the original.

\subsection{Perspectives on adaptation}

We find two major perspectives on the process of adaptation. One approaches adaptation from a semiotic point of view and is concerned with how the aesthetics and content of a work is adapted from one sign system to the other [see for instance [15]. Another takes the point of departure in the question of narrative we could call it the story approach, which is quite close to the transmedial narrative perspective. It discusses how a story can be adapted from one media to another and which aspects of the story is most important to adopt in this process ([3],[4]).

While wishing to avoid a meaning-centric or storycentric point of view, we acknowledge that in studying particular actualisations of a transmedial work, it can be fruitful to look at how this particular actualization produces new meaning-bearing content - content which can then be reproduced or reused in forthcoming actualizations of the world. For this purpose, the semiotic concept of transcoding discussed by for instance Rifkin [15: p.10] might be useful. Following Rifkin, when a world is presented in a new media form, we should be looking for elements which have been recoded into the new actualization of the world, both expanding on and yet being faithful to meaning and worldness implied within the ur-actualization. Hence, questions of fidelity and spirit are important, also in transmedial world theory.

Fidelity in adaptation is a question Dudley Andrews has examined in his classic article “Adaptation”, where he argues that fidelity of transformation can either take 
place in the letter (literally) or in the spirit, either for instance adopting a plot scene by scene or just in essence $^{3}$. This fidelity of transformation will always be at play in an actualization of a world, because in order to maintain the essential worldness of a transmedial world and to be true to its cult status, a certain amount of fidelity is always required. Any instantiation of a transmedial world must be faithful to the original setting and story of the universe. It will always refer to the uractualization of the world as the "cultural model" to which all other models (or sign systems) refer.

\subsection{The textual fallacy in transmedial discourse}

Whether specifically discussing adaptation or transmedial concepts, many theorists have a tendency to stay within the textual realm of the work in question. Questions of adaptability or transmediality are often discussed either in relation to adaptation following either the original story told or the "deep structure" or pattern of a particular text: "narrative is a deep structure quite independent of its medium” [3: p. 403]. With reference to Wimsatt \& Beardsley's concept of the "intentional fallacy" [21], we could call this the "textual fallacy" the tendency to approach transmedial objects from a too literal point of view. Questions of originality, authorship or narrative events might be relevant to discuss, but in order to fully understand what a transmedial world is, we need to move away from the idea of the world as a material entity or single text, from which one true meaning can be abstracted. A transmedial world is an abstract idea of a world generated on the grounds of the first actualization of the world and the core elements this world contained, but not in anyway restricted by this. We must thus approach transmedial worlds exactly as worlds, not as a "texts" or any given sign system, but as imaginary constructs shared by the cult audience with an interest in the universe, or twisting Foucault a bit, thinking of them as transdiscursive entities [7: p.134].

We can take the transdiscursive idea even a step further, because the transmedial world is not just transdiscursive, generating multiple works, but also transsystemic, generating worlds which are actualized in many different sign systems.

\section{A framework for analysing the TMW}

\footnotetext{
${ }^{3}$ An example here could be Jane Austen's Emma which, in a very literal version, has been produced by BBC in the exact same setting as the book, with period costumes and use of sentences directly from the novel; and as a contrast has also been adapted into the Hollywood movie Clueless which is set in our time and center around a highschool teenager, yet remains faithful in spirit to the main themes of novel: matchmaking, confusion of interests and the coming of age.
}

If we are to analyse the life of a transmedial world from a transsystemic point of view, we need to begin by studying the ur-actualization of the world and the core elements which seem to define its worldness. First then, will it make sense to begin study worlds at the textual level, such as that of for instance story and plot. Later, a concrete analysis of an actualized world in a digital setting would need to take into consideration the software with which the world is implemented and the medium through which the world is filtered. These two elements together acts as the interface to world, shaping the way the user will perceive and handle the world.

\subsection{The core elements of TMW}

Which core features can we find in all transmedial worlds? We propose the following:

Mythos: the establishing conflicts and battles of the world, which also present the characters of the world. The mythos also includes stories of or rumours about certain lore items and creatures which are unique to the world. One could say that the mythos of the world is the backstory of all backstories - the central knowledge one needs to have in order to interact with or interpret events in the world successfully.

Topos: the setting of the world in a specific historical period and detailed geography, such as a futuristic technological world (science fiction) consisting of desert planets; a world set in the middle ages with fantastic elements ("fantasy") and a wild nature inhabited by raging beasts; or a crime-ridden underworld (for instance detective/gangster style) laid out in a dystopic and immense cityscape where people use both laserguns and amulets etc. The actual space and time of an actualization of the transmedial world can be changed, but the general space and time of the universe is normally unchangable, (i.e. the world will always be set in the past or the future according to the time of the ur-actualization). However, newer actualizations of a world might often be set either before or some time after the mythic time of the urtransmedial world in order not to interfere with the mythos. From the player's perspective, we can say that knowing the topos is knowing what is to be expected from the physics of and navigation in the world.

Ethos: this is the explicit and implicit ethics of the world and (moral) codex of behaviour, which characters in the world are supposed to follow. How does the good and the bad behave, and what behaviour can be accepted as "in character" or rejected as "out of character" in that world. Thus ethos is the form of knowledge required in order to know how to behave in the world. 


\section{Cyberworlds as transmedial worlds}

Deriving from Klastrup's definition of virtual worlds [12], we understand cyberworlds to be computermediated, networked and spatially navigable multi-user environments. They contain the possibility to interact in real time with other users and to actively interact with and influence the world itself. They can be game worlds or entertainments world or social worlds, but most cyberworlds provide all three opportunities (gaming, being entertained, socialising) in some form.

Cyberworlds offer some interesting opportunities for the actualization of a transmedial world. They let the user of the world become and act as a character in the world, not just experiencing the world from the outside, but actually being transported inside it. In addition, since they are multi-player worlds, they offer the opportunity of interacting with other players which share the same interest and knowledge of the transmedial world. Furthermore, they can offer the user the opportunity to explore in real time the geography of both the original and perhaps also the expanded universe of the world. However, the ultimate success of a transmedial cyberworld depends on how the designers are able to implement and expand on the mythos, topos and ethos of the ur-transmedial world.

In what follows, we will take a brief look at some well known transmedial worlds to see how they are and could be 'adapted' to a cyberworld format and how successful this actualization has been with regards to the implementation of the tree core elements mentioned.

\subsection{A world of worlds: Lord of the Rings}

We can only do a very brief introduction here to this the most archetypal of transmedial worlds, followed by a brief look at one of the digital instantiations of this particular transmedial world ${ }^{4}$.

Mythos: The creation of Middle Earth and the different

races as detailed by Tolkien ${ }^{5}$. The history of its people and races, communicated by the author throughout numerous works.

Topos: Middle Earth, its languages, its poetry and tradition.

Ethos: The fight of good versus evil, the love of nature and beauty, the idea of an higher order than the material, an exaltation of friendship, the promotion of heroic qualities such as devotion to one's king or acceptance of

\footnotetext{
${ }^{4}$ Not a multiplayer one, but it reveals some of the inherent problems of cyberworld incarnations.

${ }^{5}$ Not only in The Lord of the Rings trilogy, but also in the Silmarillion and other works.
}

duty and willingness to sacrifice personal goals for the collective good.

The Lord of the Rings: The Fellowship of the Ring ${ }^{6}$ was the first of the three games released throughout the period in which Peter Jackson launched his movie trilogy. The game's plot does not follow the movies' though, but keeps closer to the books. In this action adventure game, the player controls three different characters: Frodo, Aragorn and later Gandalf. There are no puzzles to speak of, but very simple quests and a lot of fighting. The story is very linear as it has to adjust to the plot development of the original book.

Topos: The scenarios of Middle Earth are very well reproduced; there is a good sense of space, appropriate music and decent voice acting. They are not as beautiful as in the Peter Jackson's movies, but since this is another medium we expect different conventions and limitations. The experience of exploring the world is however extremely powerful.

Mythos: It is not explicit, but it can be seen behind the scenes; for instance in the encounter with Tom Bombadil and his mysterious "Eldest, That's what I am", which fans will immediately relate to the wider mythos.

Ethos: This is where the illusion completely breaks apart. None of the above mentioned themes appears, except for the fight of good (the player) versus evil, but even this is nearly completely devoid of transcendence. The player has the impression of spending all her time fighting (using a rather cumbersome fighting system) and getting really inane quests that go against the ethos of the story. The first time that Aragorn appears (in Bree) he gets the following quests: find Merry (who is lost in the village), collect some clothes, collect some melons, collect some hay bolsters, and collect some small logs. It is very hard to recognize the heroic Aragorn from the transmedial world in this one, who is running around picking up melons while fleeing wolves ${ }^{7}$.

Quests only gain significance if you can relate them to the transmedial world ${ }^{8}$ For example, the first hard quest is to avoid the black riders in order to leave the shire, something that took us quite a few attempts filled with dread at the perspective of being caught by the evil beings. When we finally suceeded, it was with a great sense of triumph and achievement. This quest is actually part of the original story (even if in another form). The problem arises when in order to create more gameplay,

\footnotetext{
${ }^{6}$ The game was developed by Surreal Software and published by Black Label Games in October 2002. We played the Playstation 2 version.

${ }^{7}$ Actually, a way to avoid being killed is to let the hobbits stand between Aragorn and his enemies, because they, as non-playing characters, cannot get killed, and will finish off your enemies for you. Nothing could be more against the ethos of the transmedial world.

${ }^{8}$ For an introduction about quests in computer games, see Tosca 2003.
} 
the designers expand the cyberworld with meaningless, against-the-transmedial-ethos, quests .

\subsection{Non-transmedial cyberworlds}

There are a number of massive multiplayer online games that do not spring from any transmedial world, but still we can look at how they relate to these ideas in order to find possible reasons behind at least a part of their success or failure.

EverQuest ${ }^{9}$ is the most successful Western MMORPG to date for several reasons: the good quality of the graphic world, the opportunities for players to explore vast territories, the pleasures of advancing the customizable characters, and, most importantly, the enjoyment of the collaborative interaction with other players in order to achieve results. However, the problem of not having a transmedial world to refer to is that the actions of the player characters cannot be related to any meaningful universe behind, and that is also why serious roleplaying is impossible, as Tosca has discussed in a previous article [19]. EverQuest picks up the superficial traits of the fantasy genre (the medieval society, the different races, etc), and tries to create its own mythos and ethos of chivalry (both in-game and in the game package and other marketing objects), ultimately unsuccessfully, we argue, as the strength of cyberworlds is not the telling of stories, as we discuss below.

Matt Firor, who was involved in the development of Dark Age of Camelot $^{10}$ reflects on why this game was successful. "Having a recognizable background to the game would go far toward making the game more appealing to players." [14: p. 340-341] Even without being a specific transmedial world, the Arthurian theme is directly related to a recognizable body of legends, made popular through countless incarnations in different media, something that was a key factor in the success of this game.

Gaute Godager, of Funcom, says of Anarchy Online's ${ }^{11}$ backstory that they wanted to have something non-linear that people could influence [14: p.304], which they called the "Funcom Universe", a true fairy tale, where people chose sides and played out their dark or white destiny" [ibid.] However, the story was "a disappointment to many players" (14: p. 305) because it did not achieve the promised interactive heights. So even though the conflict of the clans kept players interested, the story eventually lacked the desired depth that it would

\footnotetext{
${ }^{9}$ Developed and published by Sony Online Entertainment. Its first version launched in February 1999.

${ }^{10}$ Developed by Mythic Ent and published by UV Games in October 2001.

${ }^{11}$ Developed and published by Funcom in June 2001 .
}

have had if it had been part of a transmedial world, we would argue.

\subsection{A successful transmedial cyberworld: Star Wars Galaxies}

One of the most prolific transmedial worlds of the two last decades is the Star Wars Universe presented first in the 1980's movies, immediately establishing a huge cult following. In recent years, the world has a revival with a new wave of films laying out the "backstory" of several of the characters we got to known as grown-ups in the first films. On parallel lines, several new computergames have been released, expanding on the universe and the mythos, as is the case with the very popular Knights of the Old Republic game, which takes place several thousand years before the rise of the empire. The latest addition to the universe is the cyberworld and massive multi-player game Star Wars Galaxies (SWG) which was launched online in 2003 and has already passed the magical 100.000 subscriber limit.

Mythos: the SWG producers state that this world will allow players to "live the Star Wars movies in a way they never have before" [22] and the claim to fidelity towards the original movies is apparent throughout the gameworld, from the beginning of the game which opens with the famous scrolling text on a black universe background, presenting the current setting of the story.

When designing a character, following the original story, the player can choose to fight either on the side of the rebels or the empire or to stay neutral. Favourite characters from the movies have been incorporated into the world as non-playing characters which can give your character missions to fulfill; however you are not yourself allowed to play any of the known characters from the universe - in this way, they remain immutable.

SWG also emphasises the aspects of multiplicity of "life forms" which are a salient characteristics of the urtransmedial Star Wars world. ${ }^{12}$ The player is presented with the option of playing eight different races. Droids, almost as human as R2D2 and C3PO abound as computer-controlled characters. One could argue that a certain amount of techno-fetichism combined with more magical abilities is one of the traits that make Star Wars stand out as a world: and indeed, also in this actualization of the world is possible to obtain the most desirable object of all: the lightsabre, the yielding of which requires the mental capabilities of a jediknight, a character class the player has to work hard to deserve.

\footnotetext{
12 The fascination of life forms is taken even further in the Knights of the Old Republic game where many of the races you meet speak each their language (consequently implemented in the game with voice acting). Currently, most races in SWG speak English.
} 
Topos: like the first transmedial world, Star Wars Galaxies is set in a "galaxy far, far away" and currently entails the possibility to visit ten different planets. Some of these are known from the first movies, such as Tatooine, the home planet of Luke Skywalker, however some of the planets are known from the "expanded universe" of the original films which has been elaborated upon in the cult literature, games and later films. Both originals planets and races and later additions are referenced on the Star Wars Encyclopedia Site (www.starwars.com) which serves as a useful reference guide in further world creation.

Ethos: The main ethical decision in the Star Wars Universe has always been whether to follow "the dark side" or the right side of the force. It is worth noting that both the Knights of the Old Republic and the Star Wars Galaxies gameworld offer players the possibility to become both a good and an evil jedi. This is recognition of the fact that users might not always want to comply with the "honourable code" of a world, but will as likely want to follow the evil path, as long as the evil code is also clearly stated in the layout of the universe.

However, although many known characters and items have been made part of the game, the fact that they in order to remain untouchable, have been assigned to be non-playing characters (NPC's) has actually made them act "out-of-character", which has caused major complaints from the players in the game forums. ${ }^{13}$

To sum up, our analysis of some known transmedial worlds and their digital and cyberworldly manifestations indicate that adhering to both the mythos, topos and ethos of the world help ensure a positive user response. Following, in the light of the discussions here presented, can we now give any recommendations as to how designers could use these ideas in the cyberworld design process?

\section{Using TMWs in the design process}

Examining the main game design manuals, we find that a few designers have dealt with aspects related to our discussion about transmedial worlds, but none of them has really incorporated this way of thinking.

In their 2003 book, On Game Design, Rollings and Adams give recommendations about world design ${ }^{14}$, describing five dimensions of a game world: the physical,

\footnotetext{
13. "Look at C3PO's dialogue, for example. It simply does NOT sound like him. It sounds like a MMOG designer assigning a quest. Second, give rewards on the quests that feel special--NOT powerful items, but unique, "Star Warsy" trophies and tokens, just fun things that say, "I did the quest!". There's nothing more immersion-breaking than having a Rebel doctor hand you a broken viewscreen. That just feels idiotic. [23] ${ }^{14 .}$ Specifically in the chapter "Game Settings and Worlds" [16].
}

the temporal, the environmental, the emotional and the ethical. The physical dimension is about the visual aspect of the world, the temporal is related to gameplay (i.e. turn-based or real time), the environmental has to do with the cultural context (backstory, setting as related to our world, etc.), the emotional is about making players care about the game and experiencing adult emotions, and the ethical dimension about what kinds of behaviours will be possible in the game (i.e. how violent will it be).

In general they are quite worried about the originality of the game world. In their "environmental dimension" they declare it boring to use fantasy settings inspired by Tolkien, and encourage designers to try to make it different by finding new sources of inspiration, like Islamic Spain, "Valhalla, in Russia under Peter the Great, in the arctic tundra, at Angkor Wat, at Easter Island, or at Machu Pichu" [16: p. 73]. They go as far as to recommend not to use settings that will be instantly recognized by players, such as a grim Blade Runner like future [16: p. 74]. As intriguing as this might sound ${ }^{15}$, this approach does not take audiences into account, so that what seems original to the designer might not work, because people do not share the necessary references in order to become immersed in that particular world. It also misses the possibility of drawing upon world knowledge that people might have from other media.

The book, Developing Online Games: An Insider's Guide, by Mulligan and Patrovsky, is written from a technical and business oriented point of view without specific content guidelines. It is interesting that for them, "in the end, an online game is really just a mechanism to allow players to socialize in a context" [14: p.139], which is also very important to us in our understanding of cyberworlds.

Mulligan and Patrovsky also argue that players do not want to be told a fixed story that they cannot influence. They recognize the need for providing some background story for the online game "if only to assist the player in suspending disbelief and deriving more entertainment value from your game." [14: p.146]. But it is a mistake as designers to try to impose an own one outcome, because the most compelling content will always be playercreated, if you allow them to affect the world in some manner. ${ }^{16}$

This reinforces our idea of cyberworlds being the most appropriate vehicle for players to perform the transmedial world content, which would also solve the

\footnotetext{
${ }^{15}$ Mulligan and Patrovsky relate these overused themes to the Western orientation of game designers, posing it as a marketing problem: : "it won't matter how large the total market grows if you base your games on Western mythology and deliver them in English only" (13)

16 "An example of this might be two members of separate guilds getting "married" in the game, thus ending a faction war that had made the area dangerous for all players to move around in without getting killed" (147)
} 
problem of the "imposed story" that Mulligan and Patrovsky criticize, since they can be told the foundational story in other media (books, films etc).

In his book, Designing Virtual Worlds, Richard Bartle also deals with practical aspects to take into consideration when designing a world (scope, geography, population, physics and "major decisions" regarding for instance ethics or economy). Notably, in the introduction he claims that some genres are more suited to "adaptation" into a virtual world format than others. For him, the success of a virtual world (or a cyberworld) is independent of its genre: "The chief importance of genres lies in their ability to attract players. From this perspective, the choice of genre becomes a marketing issue, rather than a design issue” [2: p.41], which seems to us a very strange claim, since players will cognitively frame the game according to genre, and therefore it is a key design issue. Likewise, choosing a TMW as the framework for one's design should make a lot of design issues much easier to handle.

\section{Conclusion}

We have put forward the claim that transmedial cyberworlds allow the players to interact within a known and shared context, where they can be creators of their own stories - and be able to expand the universe themselves by making player-built cities, objects etc. However, the success of cyber-transmedial world depends on the designers' ability to identify and implement the core elements of the ur-world without betraying its topos, ethos and mythos.

Our analysis suggests that cyberworlds which concentrate on the performative aspect (letting players create their own content) yet still refer consequently to the mythos, topos and ethos of the ur-world will be more successful than cyberworlds which try to retell or modify the mythos of the ur-world or try to impose their 'own' storyline. Relying on a transmedial world can also solve some of the most poignant problems of storytelling in computer games, such as excessive linearity and quests which do not make sense to the dedicated player.

\section{References}

[1] Aarseth, Espen. 2000. "Allegories of Space: The Question of Spatiality in Computer Games" in Markku Eskelinen and Raine Koskimaa (eds.) Cybertext Yearbook 2000. Jyväskylä: University of Jyväskylä Press.

[2] Bartle, Richard A. 2003. Designing Virtual Worlds. Boston: New Riders.

[3] Chatman, Seymour. 1981. "What Novels Can Do that Films Can't, (and Vice Versa)." On Narrative. Ed. W. J. Mitchell. Chicago: U. of Chicago P. Pp. 117-136.
[4] Dudley, Andrew. 1984. "Adaptation" in Concepts in Film Theory.Oxford:Oxford University Press. Pp. 96-106.

[5] Dudley, Andrew.1976. The Major Film Theories: An Introduction. New York: Oxford University Press.

[6] Fish, Stanley. 1980. Is there a text in this class? The Authority of Interpretive Communities. Cambridge, MA: Harvard University Press.

[7] Foucault, Michel: "What is an author" in Twentieth Century Literary Theory (ed. Lambropoulos \& Miller). NY: State University of New York Press, pp. 124-144.

[8] Iser, Wolfgang. The Act of Reading. A Theory of Aesthetic Response. The John Hopkins University Press, Baltimore, 1980. [9] Jenkins, Henry. 2003. “Transmedia Storytelling” in the "Digital Renaissance” column of the Technology Review. Boston: MIT Press. January 15, 2003

[10] Juul, Jesper. 2003. Half-Real. Video games between real rules and fictional rules. Copenhagen: IT University of Copenhagen. Doctoral thesis.

[11] Iser, Wolfgang. The Act of Reading. A Theory of Aesthetic Response. The John Hopkins University Press, Baltimore, 1980 [12] Klastrup, Lisbeth: Towards a Poetics of Virtual Worlds Multi-User Textuality and the Emergence of Story. Copenhagen: IT University of Copenhagen. Doctoral thesis.

[13] Lacey, Nick. 2000. Narrative and Genre. Key Concepts in Media Studies. Hampshire: Palgrave.

[14] Mulligan \& Patrovsky. 2003. Developing Online Games: An Insider's Guide. Boston: New Riders.

[15] Rifkin, Benjamin.1994. Semiotics of Narration in Film and Prose Fiction. New York: Peter Lang

[16] Rollings \& Adams. 2003. On Game Design. Boston: New Riders

[17] Ryan, Marie-Laure. 2001. "Beyond Myth and Metaphor The Case of Narrative in Digital Media” in Gamestudies, vol.1, nr- 1,2001.http://www.gamestudies.

org/ 0101/ryan/. Last accessed 2004/05/05.

[18] Sitarski, Piotr. 2003. "Narration in Computer Games and in Entertainment Systems”. Poster in Level Up. Digital Games Researchers Association Conference, Utrecht, the Netherlands. November 2003

[19] Tosca, Susana. 2003. "The Quest Problem in Computer Games". In Proceedings of TIDSE 2003, Darmstadt, Germany, March, 2003.

[20] Tosca, Susana. 2002. "The EverQuest Speech

Community". CGDC 2002 Proceedings. University of Tampere: Finland, 2002.

[21] Wimsatt, W.K, \& Beardsley, 1987: “The intentional fallacy” in Twentieth Century Literary Theory (ed.

Lambropoulos \& Miller). New York: State University of New York Press, pp.103-115.

Sites

[22] Star Wars Galaxies FAQ.

http://starwarsgalaxies.station. sony.com/faq.jsp?page=FAQ.

[23] Star Wars Galaxies Player Forum.

http://forums.station.sony.com.

[24] Star Wars Encyclopedia. http://www.starwars.com/. 